\title{
A Comprehensive Assessment of Drought and Climate Change
}

\author{
Qian yimin ${ }^{1}$, Shuiping $\mathrm{Yao}^{1}$, Kun Yan ${ }^{1}$, Wenjia Tang ${ }^{1}$ \\ ${ }^{1}$ Zhejiang Institute of Hydraulics and Estuary, Hangzhou 310000, China.
}

\begin{abstract}
Drought is one of slow onset natural hazards with great impacts in many aspects, such as economy, agricultural and human health. To well manage drought, the areal coverage, duration and frequency can be analyzed and estimated to provide insight into historical perspective of drought events as well the long-term variation of climate in the study area.This study tries to explore the natural of drought including its definitions, categories, trigger mechanism and possible mitigation methods. This research studies the drought characteristics in Wyoming, United States based on the rainfall data from the U.S Historical Climatology Network (USHCN). The main approach is Standardized Precipitation Index (SPI), which provides the means to analyze drought at different time scales and discusses the relationship between drought and climate change.
\end{abstract}

\section{Introduction}

Drought is a natural feature temporarily affecting most regions of the globe. It is more than just a simple water deficit. It is a complex interaction between (1) precipitation deficiencies and natural evapotranspiration (2) the demands of human life and environmental water use[1] The shortage of water results in reducing the quality of life and economy. Due to the less predictable features of drought events in terms of initiation, termination, seriousness and frequency, drought can be recognized as both a disaster and a hazard. On one hand, it is a disaster to agricultural and natural ecosystem and other human activities, because it comes with the change of precipitation regime, resulting in the interruption of water supply. On the other hand, like other natural hazards, it is a natural accident with erratic appearance but at the same time with recognizable recurrence.

Assessment and evaluation of drought events is very important for water supply management. It requires understanding recorded drought events in the area as well as the influences of droughts during their appearance. Thus, thorough knowledge of different aspects of droughts is vital for developing models to study the drought characteristics. The motivation of this dissertation is due to the global drought events that have increased during recent years, which are discussed as follow:

This dissertation focused on meteorological drought events, including definition, mechanism, measurements and the relationship between climate changes and hydrological drought for a specific site in the US.

\section{Impact of Climate Change on Drought}

In twenty-first century, climate change has been one of the most serious threats to the whole world. As the study reported by the Intergovernmental Panel on Climate Change [2], based on the instrumental observations the global temperature have risen obviously, over the past 157 years[2]. For the global scale, in the last century the warming trend has occurred in two stages, from the $1910 \mathrm{~s}$ to the $1940 \mathrm{~s}$, the degree of increase is $0.3^{\circ}$, while from the 1970 s to the now the growth has increased by $0.55^{\circ}$. In addition, during the past 12 years, 11 warmest years have occurred, the warming trend aggravates the global hydrological cycle[3]. These records illustrate that the earth's average surface temperature has been increasing significantly. As a result, the global precipitation, evaporation and runoff are increasing as well [4].

There is a large amount of studies on how climate change will influence the whole environment worldwide, many of these studies regard the effect as the result of change in precipitation and temperature, however, the influence vary form region to region due to the different type of catchments[5].

Currently, it is acceptable that drought will pose a serious threat to natural environment, sensitive ecosystem. For human beings, droughts can influence agriculture to a large extent, it is necessary to understand droughts' influences of different regions around the world over past several years, so that potential future impacts can be assessed to help develop methods to reduce the influence of drought and save livelihoods of those who depend on agriculture.

There is no doubt that global climate change continuous, in fact, in the recent years this phenomenon has been reinforced [6] Here, climate change is used as IPCC (2001) described: 'climate change refers to any change in climate over time both natural variability and results of human activities'. 


\section{Methods for Drought Identification}

Drought indices are essential tools to detect, monitor and assess drought events, a good drought index is very useful for defining different kinds of drought characters, such as the duration, intensity and severity, moreover, it is a prime tool for evaluation the impact of a drought [7]. However, due to the fickle character of this natural hazard, there are many methods and techniques employed for defining droughts, which are often conflicting, drought indices, face the same problem that there is no single and universal drought index, either. Drought indices have been developed in different domains, the area of hydrology, meteorology, agricultural or application research, remote sensing and water management[8]. The following section will discuss commonly used drought indices.

\subsection{Palmer drought severity index (PDSI)}

The Palmer Drought Severity Index is one of the best known drought indices, which has been widely applied for large-scale region researches on soil moisture and meteorological drought due to its genetic applicability[9]. This type of index has been widely employed for measuring the areal extent and severity of drought events, as well as the evaluation of the spatial and transient drought features[10]. It also helps to investigate the behavior of drought for period and monitoring the trend of hydrology change [11].

Although PDSI has been widely applied, the limitations have been documented by several researches, which can be concluded as follow [12].

1.Due to its inherent time scale, this index is more suitable for agricultural drought assessment than for hydrologic drought.

2.In PDSI, rainfall amount used to represent the all precipitation so during winter and high elevation period the values might be inaccurate. In addition, the runoff is often underestimated due to the assumption.

3.PDSI cannot respond quickly to developing and increasing drought. In addition, it is very sensitive to temperature and precipitation.

\subsection{Standardized precipitation index (SPI)}

This type of index was used for defining and monitoring drought. SPI allows researchers to determine the intensity of a drought at a given time duration for any rainfall station with data. For any region, it is based on the long-term precipitation record during a long period. The index can also be used to evaluate the wet events over a period[12]. This kind of long-term record is fitted to a probability distribution, then the distribution transformed into a normal distribution so that the mean SPI for the location and the period is zero [13].

One of the fundamental strength of the index is flexibility which allows it be calculated for several time scales. Thus, it can monitor both short-term water resources such as soil moisture and long-term water resources such as groundwater supply, reservoir level and streamflow, Another advantage is drought severity assessment by the early warning of the index.

The limitation of SPI is the only parameter of SPI is precipitation, so the length of precipitation record plays an important role for SPI calculation [14].

\subsection{Surface water supply index (SWSI)}

In 1982, the surface water supply index was developed by Shafer and Dezman, in order to complement the Palmer index. The SWSI was designed as an indicator of surface water supply in combine with hydrological and climate features. It is computed based on monthly non-exceedance probability from historic record values [15].

This index requires four input values: reservoir storage, precipitation, streamflow and snowpack. As SWSI is based on season, during winter only snowpack, precipitation and reservoir storage are computed. While in the summer, streamflow replaces snowpack as an element in the SWSI equation.

In addition, SWSI is a good measurement to monitor and assess the impact of droughts on urban and industries water supply, its primary aim is to monitor irregularities in surface water supply[16].

While, the limitations of SWSI are also obviously, the values computed in SWSI change with spatial and time scale, thus the differences in hydrological variability would result in SWSI with different contents[17].

\section{Research Methodology and Materials}

\subsection{Study Site}

For this study, Wyoming was chosen, as the study site due to its severe drought condition. As the National Weather Service stated that, as the low level of annual rainfall amount, although storms have helped replenish mountain snowpack in recent years, there are still not enough to get back to normal runoff, which is the main source for agricultural usage and people living[18].

Wyoming's climate is generally semi-arid. Compared to most other states in the United States it is much drier and windier, much of this is due to the geography diversity of this state, In general, this state is semiarid, but due to the specific of its topography, it is also varied. This state has the second highest mean elevation in the United State at 6700 feet above sea level. Due to the high elevation, it has a relatively cool climate.

This state is very dry, for most part of the state less than $250 \mathrm{~mm}$ of precipitation received annually. So drought is a constant threat in this region, the intensity of drought condition has varied from year to year, during the last decade, warm temperatures and relatively little rainfall has made this region very vulnerable. (http://www.wrds.uwyo.edu/sco/drought/drought.html)

\subsection{Data Sets}

The historic rainfall date set is provided by the United States Historical Climatology Network (USHCN), which was compiled by the National Climatic Data Center 
(NCDC) and the Carbon Dioxide Information Analysis Center (CDIAC). USHCN is usually used for analyzing long-term climate variation. In fact, Easterling et al. (1996a) claim the USHCN is the best data set for analyzing long-term climate trends in the United States especially on regional scales. Xie et al. (1996) claim that gauge observations are the most suitable record due to their longest recording period through these observations climatology of precipitation can be defined.

For this study, rainfall data for Wyoming was analyzed from January 1950 to December 2000. Monthly precipitation data from the USHCN is used to calculate the SPI values, so that the degree of drought can be estimated. Figure4.1 show the detailed paced of observation station in Wyoming form USHCN.

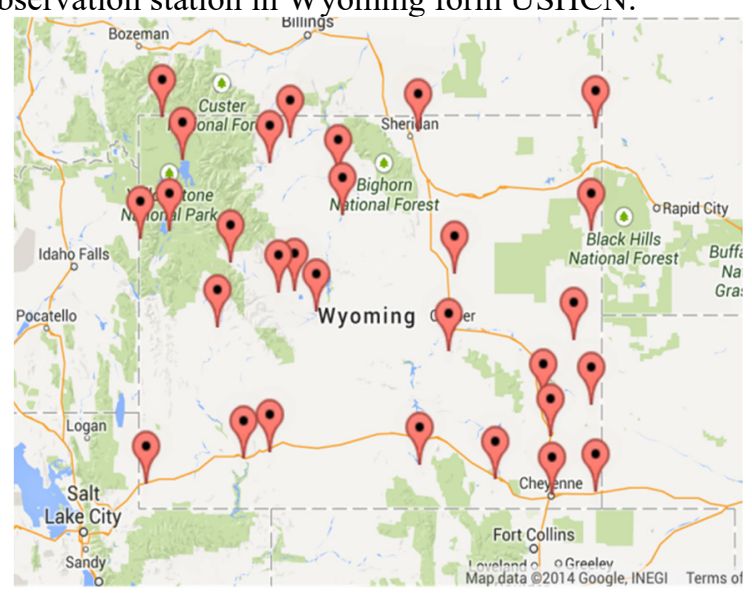

Figure 4.1. Distribution of USHCN stations across the state of Wyoming

For this study, due to the availability of data set, three airport stations are chosen as observation sites. The first one this Caper Natrona Co International Airport station with the latitude and longitude $42.8977^{\circ}$ and $-106.4739^{\circ}$ respectively and the elevation is $1619.4 \mathrm{~m}$. The second station the Lander Hunt Field Airport station, the location with the latitude and longitude $42.8154^{\circ}$ and $-108.7261^{\circ}$ respectively and the elevation of this station is $1704.4 \mathrm{~m}$. The last station is Sheridan Co Airport station, which located near the foothills of the Big Horn Mountains in Northeastern Wyoming about two miles southwest of the City of Sheridan's Central Business District,

Furthermore, in order to comprehensively assess the relationship between drought and climate change, the date set of temperature change for this site is also used, which is available from the National Climatic Data Center (NCDC).

\subsubsection{Annual rainfall data for study stations}

Figure4.2 shows that the general shape of the rainfall distribution from 3 stations is not significantly different. So the data from these three stations can be used for further work.

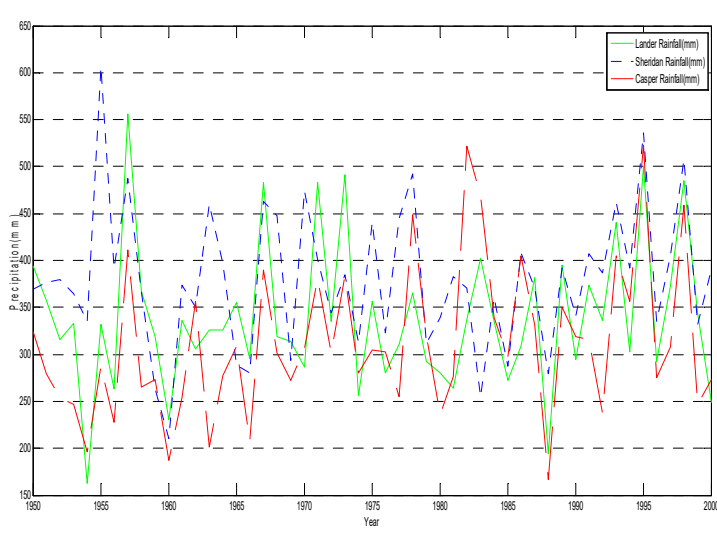

Figure 4.2. Annual precipitation changes for each station

\subsection{Research Methodology}

As discussed above, the standardized precipitation index can describe the amount of rainfall during the given time period efficiently. This type of index provides information of the amount of precipitation, in addition it acts as an indicator of what amount can be considered as a normal condition, therefore, the decision of whether a station is experiencing drought or not can be made. Besides, by plotting a time series of year against SPI provides an indicator for the drought record of the selected station. So for this study, SPI is chosen as the main method to evaluate the drought condition

\subsubsection{SPI algorithm applications}

Calculation:

From mathematical point, the Standardized Precipitation Index is based on the cumulative probability of rainfall events appearance at a station.

The main point for SPI calculation is to transform one frequency distribution (e.g., gamma) to another frequency distribution.

Generally, the first step for SPI calculation is to choose a particular probability distribution such as gamma distribution or beta distribution [12], which can reliably fit the long-term precipitation time series. Gamma distribution has been widely used, as the gamma distribution has been regarded as the reliable fit to the precipitation distribution.

This is done through a process of the maximum likelihood estimation of the gamma distribution parameters; $\alpha$ and $\beta$ put it simply This kind of process allows a mathematical cumulative probability function to represent the rainfall distribution effectively [12]. Thus based on the rainfall record, the probability that the rainfall being less than a certain amount can be calculated. The normal distribution is usually used for another transformation so that the mean and standard deviation of the SPI for a certain station and long-term period is zero and one, respectively[13].

Procedure and Formula for Computation of SPI

$g(x, \alpha, \beta)=\frac{1}{\beta^{\alpha} * \Gamma(\alpha)} x^{\alpha-1} * e^{-x / \beta}$ 
For $\mathrm{x} \geq 0$, otherwise $\mathrm{g}(\mathrm{x})=0$, the parameters $\alpha$ and $\beta$ satisfy $\alpha>0, \beta>0$.

For $\alpha>0$ the gamma function $\Gamma(\alpha)$ is defined by

$\Gamma(\alpha)=\int_{0}^{\infty} x^{\alpha-1} e^{-x} d x$

Then $\alpha$ and $\beta$ parameters need to be estimated through the maximum likelihood estimation using the approximation of

$\hat{\alpha}=\frac{1}{4 A}\left(1+\sqrt{\frac{4 A}{3}}\right)$

$\hat{\beta}=\frac{\bar{x}}{\hat{\alpha}}$

For $\mathrm{n}$ observations

$A=\operatorname{In}(\bar{x})-\frac{\sum \operatorname{In}(x)}{n}$

The next step is to integrate the probability density function with $\mathrm{x}$ and attach $\alpha$ and $\beta$ parameters and produce the cumulative probability distribution function $\mathrm{G}(\mathrm{x})$ :

$$
G(x)=\int_{0}^{x} g(x) d x=\frac{1}{\hat{\beta}^{\hat{\alpha}} \Gamma(\hat{\alpha})} \int_{0}^{x} x^{\hat{\alpha}} e^{-x / \hat{\beta}}
$$

Letting $\mathrm{t}=x / \hat{\beta}$, the formulate (6) becomes the incomplete gamma distribution

$$
G(x)=\frac{1}{\Gamma(\hat{\alpha})} \int_{0}^{x} t^{\hat{\alpha}-1} e^{-t} d t
$$

Since the gamma distribution is undefined for $\mathrm{x}=0$ and a precipitation distribution may contain zeros, the cumulative probability becomes

$$
H(x)=q+(1-q) * G(x)
$$

$\mathrm{q}$ is the probability of zero precipitation.

Then, $H(x)$ is transformed into a normal variable $\mathrm{Z}$ by the way of following approximation [19]:

$$
\begin{aligned}
& \left.Z=S P I=-\left(t \frac{c_{0}+c_{1} t+c_{2} t^{2}}{1+d_{1} t+d_{2} t^{2}+d_{3} t^{3}}\right) 0<H(x) \leq 0.5\right) \\
& \left.Z=S P I=+\left(t \frac{c_{0}+c_{1} t+c_{2} t^{2}}{1+d_{1} t+d_{2} t^{2}+d_{3} t^{3}}\right) 0.5<H(x)<1\right)
\end{aligned}
$$

When $0<H(x) \leq 0.5$,

$$
t=\sqrt{\operatorname{In}\left(\frac{1}{(H(x))^{2}}\right)}
$$

$$
\text { For } 0.5<H(x)<1.0, t=\sqrt{\operatorname{In}\left(\frac{1}{(1-H(x))^{2}}\right)}
$$

And $c_{0}, c_{1}, c_{2}, d_{1}, d_{2}, d_{3}$ are following constants

$$
c_{0}=2.515517 d_{1}=1.432877
$$$$
c_{1}=0.802853 d_{2}=0.189269
$$

$c_{2}=0.010328 d_{3}=0.001308$

\section{Interpretation}

No matter the location or time scale, the SPI represents the number of standard deviations from the mean of an extreme event occurs, which is often called a "z-score". The "standard deviations" thus is often considered as the unit of the SPI. In addition, standard deviation can be explained as the value comes with a distribution when the cumulative probability of an event is $0.1587[20]$.

Through this method, the cumulative probability of any SPI value can be found, and this will be equal to the cumulative probability of the corresponding rainfall event[20]. In SPI positive values mean precipitation exceed the median precipitation, and vice versa. Due to the normalization of SPI, both wet and dry events can be represented in the same way. The following table summarizes the cumulative probabilities for various SPI values.

Table 4.1.SPI and cumulative Probabilities[21]

\begin{tabular}{|c|c|}
\hline SPI & Cumulative Probability \\
\hline-3 & 0.0014 \\
\hline-2.5 & 0.0062 \\
\hline-2 & 0.0228 \\
\hline-1.5 & 0.0668 \\
\hline-1 & 0.1587 \\
\hline-0.5 & 0.3085 \\
\hline 0 & 0.5 \\
\hline 0.5 & 0.6915 \\
\hline 1 & 0.8413 \\
\hline 1.5 & 0.9332 \\
\hline 2 & 0.9772 \\
\hline 2.5 & 0.9938 \\
\hline 3 & 0.9986 \\
\hline
\end{tabular}

For several purposes, McKee design SPI for 3, 6, 12, 24, and 48-month time scales and then classified the drought class as shown in Table 4.2. When the value of SPI is -1.0 or less then the drought event occurs. The duration, magnitude and intensity can be calculated for every drought event.[20]. Table 4.2 shows the value of SPI and its corresponding dry or wet degree.

Table 4.2.Classification of SPI values[12]

\begin{tabular}{|c|c|}
\hline \multicolumn{2}{|c|}{ SPI Values } \\
\hline 0.2 and more & Extremely wet \\
\hline 1.5 to 1.99 & Very wet \\
\hline 1.0 to 1.49 & Moderately wet \\
\hline-0.99 to 0.99 & Near normal \\
\hline-1.0 to -1.49 & Moderately dry \\
\hline-1.5 to -1.99 & Very dry \\
\hline-2 to less & Extremely dry \\
\hline
\end{tabular}

\subsubsection{SPI calculation program}


For this study, a program is applied to calculate Standardized Precipitation Index, which is relatively easy to operate. This program is already compiled and all libraries are included so all things have to be done is run the program and follow the instructions on the screen. The SPI program downloaded from ( http://www.drought.unl.edu/monitor/spi/program/spipr ogram.)

Input data are arranged in three-column format as shown below:

Header

Y M P

Y M P

Y M P

etc

Here, 'Header' means a description about the file, or something about the station.

' $\mathrm{Y}$ ' means year

' $M$ ' means month, which in the format as 1,2,3 etc

' $\mathrm{P}$ ' represents the precipitation multiplied by 100

For the three rainfall stations, data are arranged as shown above. Input files are created and one by one and SPI values are computed for each station on 1, 3, 6, 9, 12-month time scales.

\section{Results}

\subsection{Rainfall Characteristics}

For this study, rainfall analysis was done monthly and annually, the rainfall analysis for drought risk study should include precipitation amount trends, start of dry period, and number of dry month.

\subsubsection{Monthly rainfall}

Monthly precipitation is main input in SPI calculation. In order to generate these data, daily rainfall from 3 stations was used to calculate both the monthly rainfall for each station and the monthly average rainfall. Following figure, describe the trend of monthly rainfall change in each station. As this figure shows, there is no obvious difference in trends of three stations, so the data is useful and reliable.

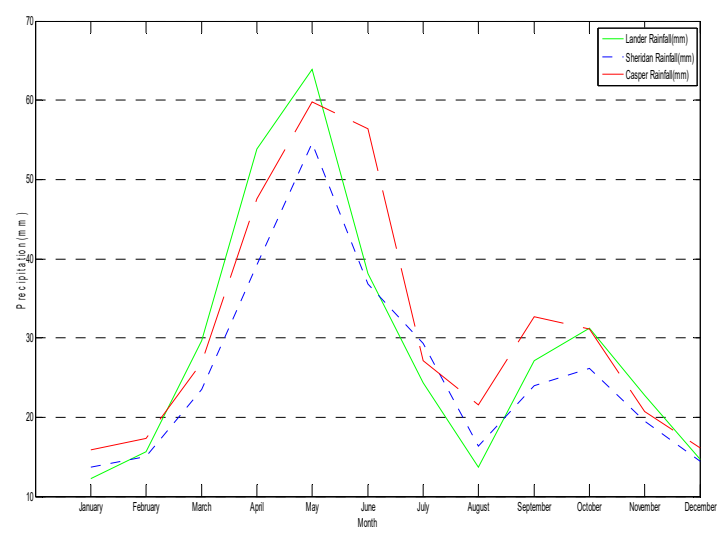

Figure 5.1. Average monthly rainfall data $1950-2000$ According to the result of monthly rainfall in each station, the values for whole study site can be estimated. Table 5.1 Statistic describes the monthly rainfall calculated from three stations of the 50 years record. Figure 4.1 shows that the general trend of seasonal distribution, as shown in this figure, the average monthly rainfall increases rapidly since the February until the maximum amount occurs in the May with $57.2 \mathrm{~mm}$, after that a rainfall downward trend follows. Among the 12 month, the lowest average rainfall record appears in the February.

Table 5.1. Monthly rainfall from three stations

\begin{tabular}{|c|c|c|}
\hline Month & & $\begin{array}{l}\text { Precipitation } \\
\quad(\mathrm{mm})\end{array}$ \\
\hline \multirow{3}{*}{ January } & Max & 51.82 \\
\hline & Min & 3.81 \\
\hline & Mean & 18.8 \\
\hline \multirow{3}{*}{ February } & Max & 58.17 \\
\hline & Min & 9.9 \\
\hline & Mean & 18.23 \\
\hline \multirow{3}{*}{ March } & Max & 57.66 \\
\hline & Min & 14.75 \\
\hline & Mean & 30.67 \\
\hline \multirow{3}{*}{ April } & Max & 84.07 \\
\hline & Min & 12.7 \\
\hline & Mean & 57.14 \\
\hline \multirow{3}{*}{ May } & Max & 119.38 \\
\hline & Min & 19.56 \\
\hline & Mean & 57.2 \\
\hline \multirow{3}{*}{ June } & Max & 109.98 \\
\hline & Min & 15.75 \\
\hline & Mean & 48 \\
\hline \multirow{3}{*}{ July } & Max & 65.28 \\
\hline & Min & 11.18 \\
\hline & Mean & 32.71 \\
\hline \multirow{3}{*}{ August } & Max & 65.79 \\
\hline & Min & 9.91 \\
\hline & Mean & 27.08 \\
\hline \multirow{3}{*}{ September } & Max & 78.99 \\
\hline & Min & 6.6 \\
\hline & Mean & 31.29 \\
\hline \multirow{3}{*}{ October } & Max & 72.9 \\
\hline & Min & 3.81 \\
\hline & Mean & 29.1 \\
\hline \multirow{3}{*}{ November } & Max & 58.93 \\
\hline & Min & 9.65 \\
\hline & Mean & 27.38 \\
\hline
\end{tabular}




\begin{tabular}{|c|c|c|}
\hline \multirow{2}{*}{ December } & Max & 58.17 \\
\cline { 2 - 3 } & Min & 5.59 \\
\cline { 2 - 3 } & Mean & 25.67 \\
\hline
\end{tabular}

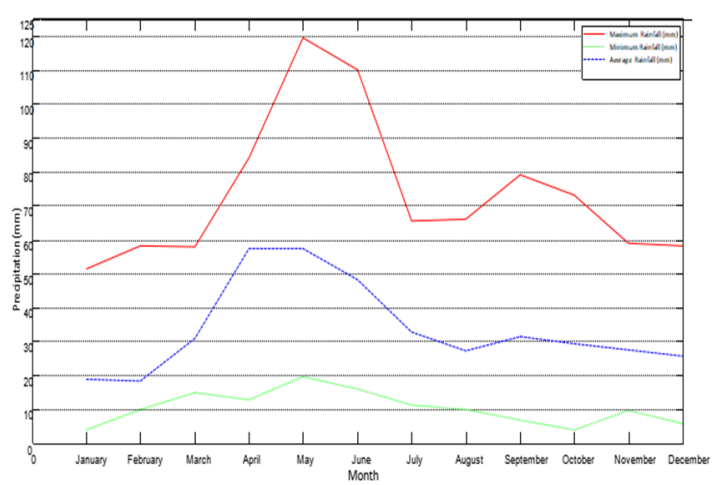

Figure 5.2. Average monthly rainfall data $1950-2000$

\subsubsection{Annual rainfall}

Rainfall data for this study site during 50 years shows the average annual rainfall as 15.86 inches $(\approx 402.77 \mathrm{~mm})$. The lowest record was $290.07 \mathrm{~mm}$ in 1988 and the highest record was $515.11 \mathrm{~mm}$ in 1995 .

The analysis of precipitation shows a slightly increase of precipitation during the period from 1950 to 2000 . Figure 4.3 shows the trend of annual rainfall in three stations and Figure 5.3 shows the trend of annual rainfall in the whole study site.

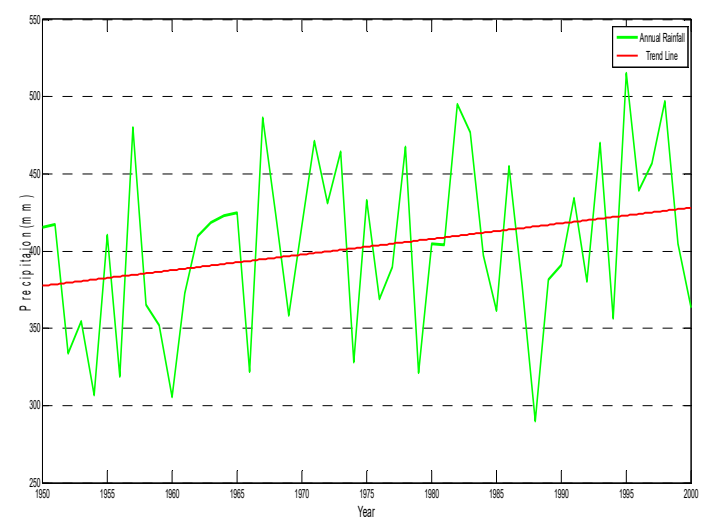

Figure 5.3. Running 12-month mean precipitation of three stations with trend line for the period January 1950 through December 2000

Meteorological drought indicates the deficiency of precipitation compared to normal rainfall record in a region. According to the Meteorological and Geophysical Agency of Indonesia (MGA), meteorological drought is defined by the percent of normal rainfall.

In this method, rainfall characteristics are divided into 3 categories[23]. They are normal, above normal and below normal. When the ratio of rainfall amount to the long time average value is between $85 \% \sim 115 \%$, then the rainfall is classified into normal rainfall, if the ratio is greater than $115 \%$, the amount of rainfall is classified into above normal. As the ratio is less than $85 \%$, the amount is classified into below normal. In this study, the threshold was set based on the average rainfall for 50 years, so the nomality means the ratio of annual rainfall amount for each year to the 50 years average rainfall amount. As shown in the Table 5.2, there are 8 years classified into drought years.

Table 5.2. Drought years

\begin{tabular}{|c|c|c|}
\hline Year & $\begin{array}{c}\text { Annual } \\
\text { rainfall } \\
(\mathrm{mm})\end{array}$ & $\begin{array}{c}\text { Normality } \\
(\%)\end{array}$ \\
\hline 1988 & 290.07 & 72.05 \\
\hline 1960 & 305.308 & 75.84 \\
\hline 1954 & 306.83 & 76.21 \\
\hline 1956 & 318.77 & 79.18 \\
\hline 1979 & 321.06 & 79.75 \\
\hline 1966 & 321.82 & 79.94 \\
\hline 1974 & 328.17 & 81.51 \\
\hline 1952 & 333.76 & 82.9 \\
\hline
\end{tabular}

\subsection{Temperature Characteristics}

In order to discuss the relationship between drought and temperature, the annual temperature form January 1950 to December 2000 is generated based on the date set from NOAA as follow. According to this fitted line, the annual temperature from 1950 to 2010 increased about $1^{\circ} \mathrm{C}$ (see Figure 5.4).

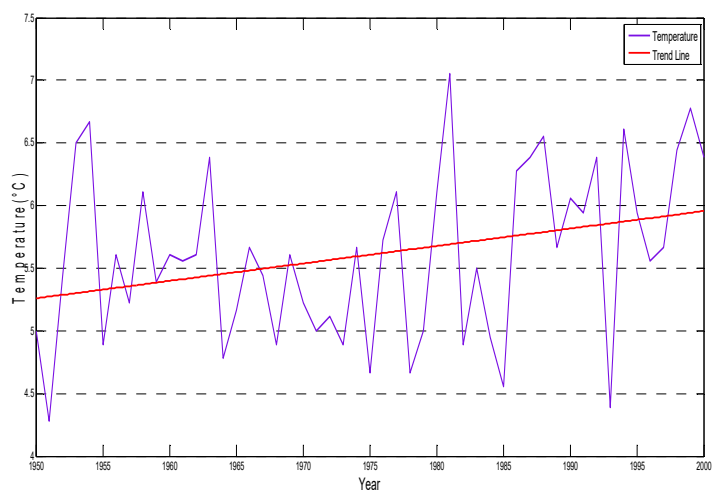

Figure 5.4. Running 12-month mean temperature of three stations with trend line for the period January 1950 through December 2000

\subsection{SPI Calculation Output}

Figure 5.5 is graph of the SPI calculated for Wyoming of the period from January 1950 to December 2000. Five time scales are shown: 1 month, 3 months, 6 months, 9 months and 12 months. This figure proves a reasonable estimate of the areal coverage abnormal dry condition at different time scales over the period. As stated by Mckee 
et al (1993) as well as shown in the graph that the frequency, duration, and intensity of drought at any special point during the whole period depend on the time scale.
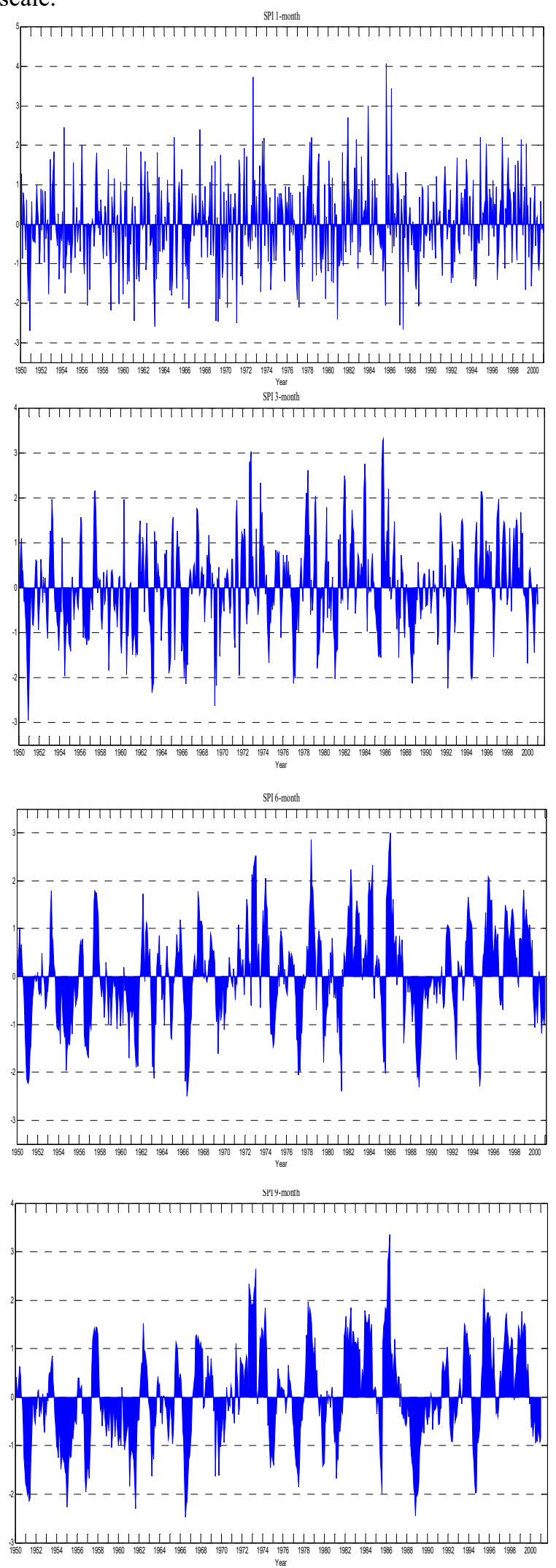

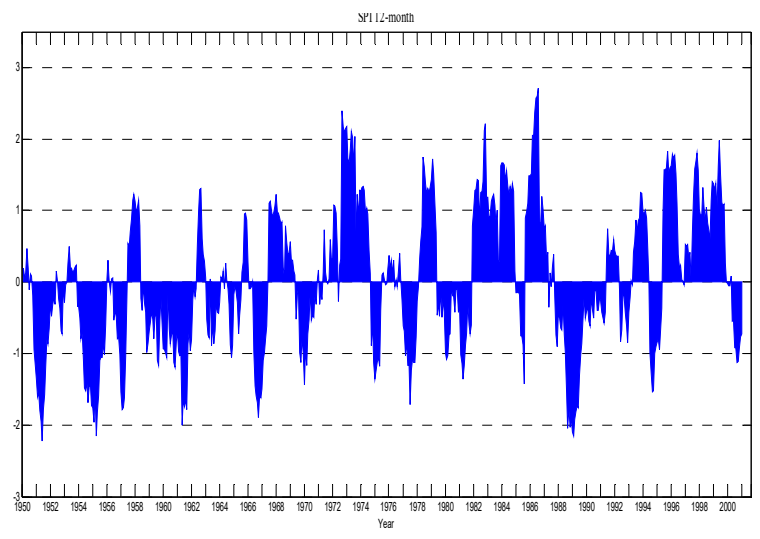

Figure 5.5. Time series of average SPI of Wyoming by time scale for the period January 1950 through December 1995

\section{Discussion and Conclusion}

\subsection{Standardized Precipitation Index Results Analysis}

SPI is calculated through the program in different time scales $(1,3,6,9$ and 12 months) with different categories of drought as shown in Table 5.1. In SPI calculation, positive values present the rainfall is great than median rainfall and negative values mean the rainfall is below the median rainfall. In dry condition monitoring, the drought part of SPI is divided into three parts: moderately dry $(-1.0<$ SPI $<-1.49)$, severely dry $(-1.5<$ SPI $<-1.99)$ and extremely dry $(\mathrm{SPI}<-2.0)$.

Table 6.1. Drought category for each time scale

\begin{tabular}{|c|c|c|c|c|c|c|}
\hline \multirow{2}{*}{$\begin{array}{c}\text { SPI } \\
\text { Values }\end{array}$} & Category & \multicolumn{5}{|c|}{ Number of months } \\
\cline { 2 - 7 } & SPI 1 & SPI 3 & SPI 6 & SPI 9 & SPI 12 \\
\hline $\begin{array}{c}2.0 \text { and } \\
\text { more }\end{array}$ & $\begin{array}{c}\text { Extremely } \\
\text { wet }\end{array}$ & 19 & 20 & 16 & 10 & 16 \\
\hline $\begin{array}{c}1.5 \text { to } \\
1.99\end{array}$ & Very wet & 24 & 22 & 33 & 36 & 32 \\
\hline $\begin{array}{c}1.0 \text { to } \\
1.49\end{array}$ & $\begin{array}{c}\text { Moderately } \\
\text { wet }\end{array}$ & 38 & 48 & 47 & 67 & 71 \\
\hline $\begin{array}{c}-0.99 \\
\text { to } 0.99\end{array}$ & $\begin{array}{c}\text { Near } \\
\text { normal }\end{array}$ & 443 & 421 & 417 & 403 & 389 \\
\hline $\begin{array}{c}-1.0 \text { to } \\
-1.49\end{array}$ & $\begin{array}{c}\text { Moderately } \\
\text { dry }\end{array}$ & 46 & 54 & 47 & 51 & 52 \\
\hline $\begin{array}{c}-1.5 \text { to } \\
-1.99\end{array}$ & $\begin{array}{c}\text { Severely } \\
\text { dry }\end{array}$ & 22 & 23 & 31 & 31 & 37 \\
\hline $\begin{array}{c}-2 \text { and } \\
\text { less }\end{array}$ & $\begin{array}{c}\text { Extremely } \\
\text { dry }\end{array}$ & 17 & 16 & 16 & 10 & 7 \\
\hline
\end{tabular}

As shown in the Table 6.1, among these five time scales, the month belong to normal category take the largest part of the study duration. Compared the shortest time scale (1 month) to the longest time (12-month), there are some differences between them, for 12-month time scale, the amount of months belong to extremely dry is much less than that in 1 month time scale. While, for 12-month time sacle the number of months belong to moderately wet and dry month exceed that for 1 month time scale. 
In summary, as the increase of study duration, the number of months of extreme weather and normal months decreased to some extent both for wet and dry condition. On the contrary, moderately wet and dry months increased slightly.

Put it in detail, according to the result of SPI calculation, the lowest SPI value in 1-month time scale is -2.7, which happened in November 1950, for 3-month time scale -2.95 is the lowest value of November 1950, -2.5 for 6-month time scale in May 1966, -2.48 for 9-month time scale in June 1966 and for 12-month time scale the lowest SPI is -2.22 in May 1951.

\subsubsection{Duration of drought periods rainfall}

McKee et al. (1993) defined a drought event when the SPI below -1.0 or less. In addition, the beginning of this drought is then defined as when the SPI begin negative and the end of the drought is then defined as the SPI goes back to zero or positive.

Figure 4.5 shows the differences of drought duration and their frequencies under different SPI time scales. The SPI values vary among the duration. The fluctuation of SPI value for SPI 1-month is the highest one. It is because the SPI 1-month is based on 1-month precipitation data that has more fluctuation than other data durations.

Put it in detail, for shorter SPI time scales such 1-month or 3-month, the high temporal frequency occurs in both the dry month $(\mathrm{SPI}<0)$ and the wet month $(\mathrm{SPI}>0)$ periods and the periods are relatively short. However, as the time scale increases, the frequencies begin to decrease. In a longer SPI time scale such as the time scale of 12-month, the figure shows that there are approximately 22 times periods among them, five important drought periods recognized: the 1951/1952 1954/1956 1958/1962 $1979 / 19821988 / 1990$ period, during these periods drought event relatively long time. Compared the five time scales SPI, as a function of the time scales, the average dry periods $(\mathrm{SPI}<0)$ duration changing significantly.

\subsubsection{Intensity of drought periods}

Figure 4.6 shows the average SPI of Wyoming of the period January 1950 through December 2000. Since the USHCN observation stations have homogeneous coverage across the whole state of Wyoming, this figure provides a reasonable evaluation for intensify of drought at different time scales over this whole period.

For the long-term, the 12-month SPI illustrates that there are 12 drought periods: 1951/1953, 1954/1956, 1988/1991, 1957, 1966/1967, 1970/1972, 1977/1978, 1980/1982, 1986, 1994/1995, and 2000. Among these drought periods, there are three drought periods recognized: period 1951-1953, 1954-1956 and 1988-1991 all of them with the SPI reach or below minus two. As the classification of drought categories, the three periods are belong to extremely dry category.
In summary, based on figure 4.5 and the results of table 4.2, the long-term drought of the $1950 \mathrm{~s}$ was the most intense. During the period of record, there is no other long-term drought comes close to match the intensity of the 1950s drought. For short- and intermediate-term drought outside of the 1930s drought, the drought of $1988 / 1990$ is severe. From the mid 1990 s, there was a low frequency of intense drought. Therefore, in the recent years some relief has been given to the drought condition in this region.

Unlike the condition of drought, intense wet periods started form 1957, as shown in the figure of SPI 12-month the most intense long-term wet period occurred in mid 1980s, especially the 1987 wet, which was the most intense short-term wet during the period of record. Additionally, from the early 1990s, there was a high frequency of intense intermediate- and long-term wet periods. Therefore, in the recent years the wet condition has been more severe than before. Compared with the dry periods, the trend is adversely different.

\subsection{Relationship between Climate Factors and Drought}

\subsubsection{Rainfall and drought}

According to the results of SPI calculation and the analysis above, drought is related to both the amount and timing of rainfall. Consider a 1-inch shortfall in precipitation over one month: if the level of groundwater is, high at the beginning and the evaporation was less than normal then the water deficit would probably not occur. While in opposite, when the level of groundwater is very low in the beginning and the evaporation is higher than normal the same amount shortfall would likely be hailed as the onset of a drought. As Karl et al (1987) stated that when a large amount of precipitation is expected, the strongest drought signal probably occurs during that time. As the figure 4.5 shows, there was a severe drought event occurred during 1988, which was associated with a failure of spring a summer rainfall normally the wettest season. However from April to July, 1988, the average monthly rainfall are $58.67 \mathrm{~mm}, 55.63 \mathrm{~mm}, 47.24 \mathrm{~mm}$, and $50.29 \mathrm{~mm}$ respectively, during this period Wyoming experienced serious rainfall deficits. Conversely, abnormally large amount of rainfall during normal dry seasons will mitigate drought.

Additionally, a decreased frequency of rain events is not the only factor that causes precipitation deficiencies. Low-intensify precipitation can also be associated with drought events. As shown in the figure of SPI 12-month, during the period from 1952 through 1953, the SPI 12-month below minus two, which means Wyoming, was extremely dry during this period. Compared with the figure of average annual rainfall trend, the amount of precipitation during this period is much lower than other years.

\subsubsection{Temperature and drought}

Droughts, especially summer droughts are often 
associated with higher than normal air temperatures. Besides, temperature changes can aggravate water supply vulnerability-ties by affecting the frequency and behavior of snowfall and snowmelt, and influencing total snowpack amounts. According to the Figure 4.4 with the trend of annual temperature change from 1950 to 2000, the average temperature increased while unlike the expected result the drought condition ameliorated during this period. This phenomenon can be explained by the graph of the 12-month mean precipitation of three stations for the period from 1950 to 2000 . As show in this figure the trend of 12-month mean precipitation increases from 1950 to 2000 and slight increases in temperature cause precipitation to fall as rain instead of snow and initiates earlier spring snowmelt, as record, water supplies in Wyoming are dependent on snow pack largely[24]. Therefore, during this period the condition of drought is ameliorated, unlike the expected result.

\subsubsection{Summary}

Based on the discussion above, drought is a severe problem in this region during the period of record. The change of drought condition is closely related to the change of climate change. Based on the figure 4.5, droughts are likely to be ameliorated as the increase of rainfall amount and temperature during the period of record.

According to the results of last 50 years, forecast can be made that if precipitation and temperature trend continues, drought condition in this region will be relived, as rainfall, snowfall and snowmelt water can make up for fresh-water supply in this area.

For the research of drought, the 12-month SPI is recommended, because according the change of SPI values the duration and intensity of drought can be figured out clearly. Moreover, it is a useful tool for the comparison of dry and wet periods in a long period.

\section{Conclusion}

In this study, the standard precipitation index was chosen as the study method to evaluate the drought condition from January 1950 to December 2000.

The evaluation of drought condition in Wyoming indicates that during the period of 1950 to 2000, Wyoming experienced several dry periods vary from moderately dry to extremely dry. The calculated SPI values clearly show that the frequency and intensification of drought vary with the different time scales. For short-term time scales such as 1-month and 3-month the frequency of drought events is much higher than longer time scales. As for long-term time scales, such as 9-month or 12-month, the duration of each drought event become clearer.

Based on the result of SPI calculated values the contiguous Wyoming as a whole has become wetter over the period January, 1950 through December, 2000, as a result, there has been a lower frequency of both short-term and long-term drought. This can be explained by the change of precipitation amount and temperature during the whole period.

In order to mitigate the impacts of drought, a number of methods were stated to improve drought management from different aspects. It is more important to plan, forecast and prepare for drought events instead of doing nothing and suffers the severe consequences.

\section{Acknowledgments}

This research was supported in part by the National Nature Science Foundation of China (51709237), The Science and Technology Plan Project of Department of Water Resources of Zhejiang Province (RA1603).

\section{References}

1. American Meteorological Society (AMS), 2004. A Statement on Meteorological Drought. Bull. Am. Meteorol. Soc. 85, 771-773

2. IPCC, 2007. Climate Change 2007: The Physical Science Basis. In: Solomon, S., Qin, D., Manning, M., Chen, Z., Marquis, M., Averyt, K.B., Tignor, M., Miller, H.L. (Eds.), Contribution of Working Group I to the Fourth Assessment Report of the Intergovernmental Panel on Climate Change. Cambridge University Press, Cambridge, United Kingdom and New York, NY, USA, p. 996.

3. Milly, P.C.D., Wetherald, R.T., Dunne, K.A., Delworth, T.L., 2002. Increasing Risk of Great Floods in A Changing Climate. Nature 415, pp. 514-517.

4. Clark, P.U., Alley, R.B., Pollard, D., 1999. Northern Hemisphere Ice-sheet Influences on Global Climate Change. Science 286, 1104-1111.

5. Lettenmaier, D.P., Gan, T.Y., 1990. Hydrologic sensitivities of the Sacramento-San Joaquin river basin, California, to global warming. Water Resour. Res. 26, 69-86.

6. Schönwiese, C. D., Claussen, M., Cubasch, U., Fischer, H., Graß1, H, Rahmstorf, S. et al. 2001. Stellungnahme zur Klimaänderung. Deutsche Meteorologische Gesellschaft.

7. Panu, U.S., Sharma, T.C., 2002. Challenges in Drought Research: Some Perspectives and Future Directions. J. Hydrol. Sci. 47, pp. 19-30.

8. Niemeyer S., 2008. New drought indices. Drought management: scientific and technological innovations. Zaragoza: CIHEAM. pp. 267 -274.

9. Dai, A.: Drought under global warming: a review, WIREs-Climate Change, 2, 45-65, 2011.

10. Lawson, M.P., Reiss, A., Phillips, R., Livingston, K., 1971. Nebraska Droughts: A Study of Their Past Chronological and Spatial Extent with Implications for the Future. Occasional Papers No. 1. Department of Geography, University of Nebraska, Lincoln, p. 147.

11. Rao, A.R., Padmanabhan, G., 1984. Analysis and modeling of Palmer's drought index series. J. Hydrol. 
68, 211-229.

12. McKee, T.B., N. J. Doesken, and J. Kliest, 1993: 'The relationship of drought frequency and duration to time scales'. In Proceedings of the 8th Conference of Applied Climatology, 17-22 January, Anaheim, CA. American Meterological Society, Boston, MA. 179-184.

13. Edwards, D.C. and T.B. McKee, 1997. Characteristics of 20th Century Drought in the United States at Multiple Time Scales. Climatology report number 97-2, Colorado State University, Fort Collins, Colorado.

14. Wu,H.,Hayes,M.J., Wilhite,D.A., Svoboda, M.D., 2005. The effect of the length of record on the standardized precipitation index calculation. J. Climatol. 25, pp. 505-520.

15. Shafer, B.A., Dezman, L.E., 1982. Development of a Surface Water Supply Index (SWSI) to Assess the Severity of Drought Conditions in Snowpack Runoff Areas. In: Preprints, Western SnowConf., Reno, NV, Colorado State University, pp. 164-175.

16. Wilhite, D.A., Glantz, M.H., 1985. Understanding the drought phenomenon: the role of definitions. Water Int. 10, pp. 111-120.

17. Doesken, N.J., McKee, T. B., Kleist, J., 1991. Development of a Surface Water Supply Index for the Western United States. Climatology Report Number 91-3, Colorado State University, Fort Collins, Colorado.

18. Wyoming Public Media, 2013: Despite storms, Wyoming could still face summer water shortages. [Online] Available from: http://wyomingpublicmedia.org/post/despite-storms -wyoming-could-still-face-summer-water-shortages

19. M. Abramowita and I. A. Stegun, Handbook of Mathematical Functions (Dover, New York, 1972).

20. National Drought Mitigation Centre (NDMC). 2000. The Standardized Precipitation Index. Available at http://drought.unl.edu/portals/0/docs/spi-program-al ternative-method.pdf

21. Guttman, N. B., 1999: Accepting the Standardized Precipitation Index: A calculation algorithm. J. Amer. Water Resour. Assoc.., 35(2), 311-322

22. National Drought Mitigation Centre (NDMC). 2007. Drought indices. Available at http://drought.unl.edu/whatis/indices.htm\#spi.

23. Hadi, W. 2001. Rainfall modeling and prediction in Indonesia. Paper on First APCN Working Group Meeting, May 2001. Seoul, Republic of Korea.

24. Stewart, I., Cayan, D., and M.D. Dettinger, 2004: Changes in Snowmelt Runoff Timing in Western North America under a 'Business as Usual' Climate Change Scenario. Climatic Change, 62, 217-232. 